\title{
Know thy student: Using a graduate student learning assessment questionnaire
}

\author{
Melinda Hermanns, Danice B. Greer \\ School of Nursing, The University of Texas at Tyler, Tyler, Texas, United States
}

Received: December 20, 2018

Accepted: February 18, 2019

Online Published: March 15, 2019

DOI: $10.5430 /$ jnep.v9n6p 88

URL: https://doi.org/10.5430/jnep.v9n6p88

\begin{abstract}
Background: Creating an online learning environment for today's adult learner that is engaging and conducive to meeting the various needs can be a challenge for any educator, new or seasoned. Understanding the students' perspectives of what they need from faculty to be successful is underexplored. Therefore, the purpose of this study was to describe the students' perspectives of their learning needs and motivation as reported in a faculty developed Graduate Student Learning Assessment Questionnaire (GSLAQ).

Methods: A cross-sectional descriptive survey design was employed and consisted of 120 non-traditional adult learners in graduate nursing school. The demographics are as follows: 100 females (83.3\%) and 20 males (16.7\%) with a mean age of 34.9 years.

Results: Five themes emerged: (1) motivation, (2) time orientation, (3) autonomy/role change, (4) caring, and (5) authentic engagement/communication.

Conclusions: Understanding students' concerns as well as their perceptions of what they need from faculty to be successful enables faculty to better communicate with the students as well as provide the needed support as expressed by the students.
\end{abstract}

Key Words: Online, Graduate nursing student, Learning needs

\section{INTRODUCTION}

Creating an online learning environment that is engaging and conducive to meeting the various needs and learning styles of today's graduate student can be a challenge for any educator, new or seasoned. A common challenge among the non-traditional adult learners in graduate nursing school, who are also practicing registered nurses, is juggling multiple responsibilities. Simultaneous responsibilities may include a full-time academic course load, managing personal life (events), and given the aging population, many are caring for their aging parent(s), working full- or part-time as well as balancing their own family roles and responsibilities. While online courses may offer greater autonomy and flexibility for the adult learner to manage their academic, personal, work, and life schedules, time management remains a common concern.

Convenience, one of the benefits of online education, is attracting students across the globe. With increasing numbers of students from a variety of geographical locations and ages/life stages, one may ponder, 'how can faculty meet the needs of a diverse set of students?' In the digital classroom, getting to know your students can be a challenge; however, not impossible as getting to know your student and understanding their individual needs is paramount. In 2001,

\footnotetext{
*Correspondence: Melinda Hermanns; Email: mhermanns@uttyler.edu; Address: School of Nursing, The University of Texas at Tyler, Tyler, Texas, United States.
} 
Prensky ${ }^{[1]}$ coined the terms 'digital native and digital immigrant'. 'Digital natives' are defined as the first generation of students to grow up surrounded by technology. Conversely, 'digital immigrants' are those of us who were not born in the digital world, but have grown to become accustom to it. ${ }^{[1]}$ Students pursuing an online degree come from a variety of diverse backgrounds and thus, it cannot be assumed they are all digitally literate. Therefore, understanding the students perspectives of what they need from the course faculty to be successful is key to student engagement, and, is pivotal to their learning, retention, and academic success. Understanding the students' perspectives of what they need from faculty to be successful is underexplored. The purpose of this study was to describe the students' perspectives of their learning needs and motivation as reported in the Graduate Student Learning Assessment Questionnaire (GSLAQ). The research questions are as follows:

(1) What are the graduate students' perceptions of what faculty can do in this course to help them be successful?

(2) What is their level of motivation?

(3) What are their perceived learning needs?

Nursing faculty at a southern university instituted a GSLAQ in one of the core graduate courses that was in line with suggested best practices to better understand students' perceived needs and assess how faculty can help them be successful in their online graduate nursing course. The GSLAQ sought to understand the students' perspective of their learning needs (needs from faculty to be successful as well as concerns). Additionally, the students' level of motivation was self-reported.

\subsection{Literature review}

While over thirty years have passed, the principles of a seminal study by Ellis ${ }^{[2]}$ remains relevant to today, "the success of graduate education depends on a student-faculty relationship based on integrity, trust, and support" (p. 575). Pelz's s ${ }^{[3]}$ three principles: (1) engagement, (2) interaction, and (3) presence are congruent with the Checklist for Online Interactive Learning ${ }^{[4]}$ outlines best practices in online learning and faculty evaluation. The checklist is divided into two categories: 1) Student Behaviors Meet Criterion and 2) Faculty-Student Interactions. In category one, faculty and student interaction is encouraged. Additionally, the use of a variety of communication techniques are recommended. In category two, the use of various communication techniques "to provide for greater empathy and personal approach than email and website alone" are encouraged (p. 6). Bain, Fedynich, and Knight ${ }^{[5]}$ reported a "direct correlation between faculty mentorship, the connection of students with program and faculty, and graduate success" (p. 5). Further, Fedynich, \&

Published by Sciedu Press
Bain ${ }^{[6]}$ discussed the benefit of "developing a new paradigm in regards to the graduate student of tomorrow" (p. 1) thus identifying the uniqueness of this generation. Faculty play a vital role in student success and retention. ${ }^{[7]}$ Knowing your students has been identified as one of the keys to students' success in an academic program.

While research has focused on undergraduate students' academic success, less attention has been focused on the adult learner in graduate nursing education. Gardner ${ }^{[8]}$ recognized this gap and recent efforts to examine graduate students is still needed. Perhaps with the increasing numbers of online graduate and doctoral programs, strategic efforts to examine this population is warranted. Therefore, this study attempts to narrow the gap and provide new knowledge of online graduate nursing education and explores the needs of students in an online learning environment.

\section{GSLAQ: A Strategy to Promote Student Success, Engage- ment, and Get to Know Thy Student}

Best teaching practices suggest ways in which faculty can help their students become successful online students: Developing trust, knowing the student, making the student feel valued/important, all of which are critical to their academic success. The fundamental principles of psychology, communication and trust are beneficial to students' academic success. Open, honest two-way communication between the faculty and student is pivotal to student success. Equally important, is trust. Developing trust, while basic to establishing and building any relationship, is also integral to their academic success. Part of fostering trust in an online class is entering into a partnership with students. Both communication and trust can aid in connecting with students. Learning who students are ("know thy student") by making connections is not only important for effective communication and trust, but also demonstrates faculty transparency. Two-way communication clearly outlining the expectations of the course in an organized manner further facilitates trust and helps to ensure students' academic success. Collaboration between the faculty and student/student and faculty also plays an important role in student success. At the beginning of any course, it is suggested that faculty provide professional information about themselves as well as their availability and best means to be contacted. Typically, an inclusion of a personal statement and/or teaching philosophy will be shared along with a faculty photograph. Sharing who you are as a faculty member and as a person helps humanize and personalize the course, and, is a great way to "get to know" each other. The researchers' personal teaching philosophies are student-centered, and, feel that it is important to get to know the students in an effort to facilitate their learning. The researchers believe that this is vitally important in an online 
program. Making connections with the students early, at the beginning of the semester, is critical. Equally important is knowing how students feel - it is important that students understand that they are not just a name or number on a roll sheet, rather faculty, recognize them as an individual (a practicing professional nurse and a graduate student) and that they are valued as a person. Similar to a face-to-face class, you would routinely see your student and you would get know your students; the online environment is no different. Using the Graduate Student Learning Assessment Questionnaire to assess their learning needs, understand their perception of faculty expectations as well as their level of motivation, the researchers firmly believe will help foster trust, increase student's success as well as student retention. Getting to know your students also allows the opportunity for encouragement and support, two areas that are also important for students' success. This is in line with the authors' personal and teaching philosophies.

\subsection{Theoretical framework}

Knowles' adult learning theory of andragogy ${ }^{[9,10]}$ was the theoretical framework used to guide this study. Knowles theoretical assumptions include: 1) Self-concept, 2) Experience, 3) Readiness to Learn. 4) Time Orientation, 5) Motivation to learn, and 6) Relevance. ${ }^{[10]}$ There are two types of adult learners: the traditional adult learner (17 - 24 years old) and the non-traditional learner (age undetermined). ${ }^{[11]}$ According to Knowles, ${ }^{[10]}$ the non-traditional adult learner is more selfdirected and goal oriented when compared to the traditional learner. While this is an asset, it is important for faculty to create meaningful assignments with a clear purpose so students do not perceive the academic assignments as "busy work". This is further reflected in their limited time due to multiple obligations. Pappas ${ }^{[12]}$ applied Knowles' ${ }^{[10]}$ adult learning theoretical assumptions to eLearning in terms of the five theoretical assumptions, but first recommends instructors survey the audience beforehand to determine any technical knowledge limitations. This is one of the purposes of administering the GSLAQ at the beginning of the semester. Pappas states, by surveying the experiences of online learners, faculty will be able to create eLearning experiences that are informative and engaging, rather than too challenging or boring. ${ }^{[12]}$ Pappas suggested application of Knowles' andragogy theory to the online educational environment includes strategies such as: creating learning experiences that offer minimum instruction and maximum autonomy (self-concept), include a wide range of instructional design models and theories to appeal to students' varied experience levels and backgrounds (Experience), using social media and other online collaboration tools to tie learning to social development (Readiness to Learn), to emphasize how the subject matter is going to solve prob- lems that an adult learner regularly encounters (Orientation to Learning), and provide a valid reason for every eLearning course, module or educational activity (Motivation to Learn). ${ }^{[11]}$

\section{Methods}

\subsection{Survey instruments}

Faculty developed a five-item open-ended questionnaire, the Graduate Student Learning Assessment Questionnaire (GSLAQ), based on the empirical literature to obtain the graduate students' perceived rationale for earning a graduate degree, their level of motivation, concerns related to taking the course, individuals needs from the faculty for student success as well as other concerns. This instrument is thus piloted in this study and has no existing reliability and validity estimates.

\subsection{Ethical considerations}

Institutional Research Board (IRB) approval was obtained to conduct the study. In accordance with IRB educational research procedures at the university a research assistant (RA) was hired to implement the survey. Through the learning management system an email and announcement was sent by the research assistant inviting students to participate in the study. Faculty was not included on any of the email correspondences to ensure anonymity. Students were notified by the RA that their participation in the study was completely voluntary, and, that faculty would not know who declined participation as participation in the study was not a course requirement and would not affect their course grade. Students who did not wish to have their GSLAQ included in this study were instructed to respond to the RA via email stating that they did not want their information used in the study. Students were provided an informed consent statement on the opening page of the Qualtrics survey. Students were required to click 'yes to agree' to participate and the Qualtrics survey would continue. Completion of the survey questionnaire was an indication of informed consent.

\subsection{Design}

The study was conducted using a cross-sectional descriptive survey design. Inclusion criteria included graduate students enrolled in health informatics courses as part of a master's in nursing program. This course falls within a graduate student's first year of the degree plan. Exclusion criteria included any university student not enrolled in Health Care Informatics course. Implementation of the GSLAQ was through a Qualtrics link in the learning management system. The RA managed the Qualtrics link, and student reminders to complete the survey, and faculty were blinded to the data until after the course ended. All $(\mathrm{N}=120)$, but one student 
enrolled in the Health Care Informatics courses completed the study survey.

\subsection{Data analysis}

Demographic data were analyzed using SPSS software version 24 (IBM SPSS Statistics for Windows, Version 24.0. Armonk, NY: IBM Corp). All of the Graduate Student Learning Assessment Questionnaires were read, line-by-line, and reread to identify commonalities and recurring words, themes, and concepts. To facilitate careful interrogation of data, notes were made to reduce the coding data. After initial coding, the researchers were not when back to review the codes and began categorizing data relevant to the research questions and repetitive themes emerged. Themes were identified from the students' responses ${ }^{[13]}$ and were thematically coded and validated by both researchers who are experienced in qualitative research. The themes were placed in a table that was developed in a Microsoft Word document along with supportive students' quotations to ensure authenticity. Key constructs and themes were searched using the 'find' function in Microsoft Word. Numeric occurrences of key word constructs and themes were counted after repeated searches and summed. This table served as an audit trail. Confidentiality of the student participants' questionnaire and demographic data were electronically secured on a password protected computer in which only the researchers had access and all student names and other identifiers were removed by the RA and reported in aggregate.

\section{Findings}

\subsection{Demographics}

Socio-demographic results show the study sample consisted of 120 students. There were 100 females $(83.3 \%)$ and 20 males $(16.7 \%)$. The mean age of the students was 34.9 years ( $\mathrm{SD} \pm 8.8$, Range: 41 [22-63]). Five course sections were included with an average group size of 24 students. Among degree tracks, family nurse practitioner students accounted for $44.2 \%(n=53)$ of the sample. Table 1 shows complete demographic variables.

\subsection{Level of motivation}

One GSLAQ item surveyed students' level of motivation (see Table 1$)$. Of note, twenty students $(16.7 \%$ noted on table as other) provided qualitative responses for their level of motivation ranging from their family, children, to improving the quality of nursing care. Lastly, the two students (1.7\%) who rated their level of motivation for graduate school as low was circumstantial due to her current pregnancy, and, the other student was a recent alumna of the same university.

Published by Sciedu Press

\subsection{Themes}

Five themes emerged from the data: (1) motivation, (2) time orientation, (3) autonomy/role change, (4) caring, and (5) authentic engagement/communication. These themes are discussed below.

\subsubsection{Motivation}

The first theme that was evident in $98.4 \%$ of responses from the GSLAQ was that of motivation which was present to some degree.

\section{Level of motivation}

Table 1 shows the self-reported levels of motivation ranged from low-to moderately motivated to highly/extremely motivated.

Table 1. Sociodemographic characteristics $(\mathrm{N}=120)$

\begin{tabular}{lll}
\hline Demographic Variables & $\mathbf{n}(\mathbf{\%})$ \\
\hline Age in years, Mean (SD) & $34.9 \pm 8.8$ & Range 41 (22-63) \\
Gender & $20(16.7)$ \\
Male & $100(83.3)$ \\
Female & \\
Race/Ethnicity & $82(68.3)$ \\
White/Caucasian & $16(13.3)$ \\
Black/African American & $10(8.3)$ \\
Hispanic, Latino & $11(9.2)$ \\
Asian & $1(0.8)$ \\
Two or more races & \\
Ethnic Origin & $110(91.7)$ \\
Non-Hispanic & $10(8.3)$ \\
Hispanic & \\
Degree Track & $35(29.2)$ \\
Business/Administration & $32(26.7)$ \\
Education & $53(44.2)$ \\
Family Nurse Practitioner & \\
Level of Motivation & $55(45.8)$ \\
Extremely high & $35(29.2)$ \\
High & $8(6.7)$ \\
Medium & $2(1.7)$ \\
Low & $20(16.7)$ \\
Other explanation & \\
\hline & \\
\hline & \\
&
\end{tabular}

"I am very motivated, if there was a scale, I would definitely be 10/10."

"I am highly motivated to do well in this program. This is not only my future, but impacts the future of healthcare as a whole. I wish to provide the highest quality of care possible and I know that it will take hard work, dedication and motivation to become the best provider I can be."

"I am extremely motivated. I just graduated with my BSN less than a year ago. I am still in 'school mode' and ready to complete all my 
education."

"Many of the students provided a rationale to support their self-identified level of motivation, and, their rationale was externally driven."

"My current level of motivation is seeing the light at the end of the tunnel, as well as the fact that my current employer pays for most of my education!"

"To better my education and be a positive role model for my children.'

Another rationale provided by students was the desire to improve the nursing profession.

"I have always wanted to be a nurse and I feel obtaining my master's degree would help to elevate the profession as a whole."

"To grow my profession."

"As senior leadership looks towards retirement, a new wave of nurse executives must assume roles and assist in ushering in this new wave of healthcare in which we currently find ourselves practicing. I strive to be a nurse who not only cares intimately about my patients, but also cares for the well-being of my colleagues. By earning my MSN/MBA, I will be poised to assume various roles in nursing administration and advocate for nurses and patients alike."

Overall, students self-identified their level of motivation as being motivated to highly motivated. Students in this class perceived themselves as being motivated and committed to success. More specifically, the majority of students indicated that they were very motivated - highly motivated to advance their education expressing their commitment to succeed as exemplified in the following statements:

"I committed myself full time into studies, and never want to end it." "Highly motivated to succeed, balancing many obligations, family, school, work." Many of the students identified family as their motivating factor as evidenced in the following in exemplars:

"I am currently very motivated to earn my degree and show my children that they can do anything they put their mind to."

"I am very motivated to continue my journey to become a practitioner!"

Others ranked their motivation as "fairly high," writing "currently, it is fairly high. However, I am feeling overwhelmed trying to get organized." While this was an open-ended question ("what is your level of motivation?"), one of the students numerically ranked her level of motivation as:

" $8 / 10$, and the only reason I say that is because I am full-time and it can be challenging to keep up with home, kids, work, and this program. I am doing well so far, so I'll try to keep the schedule. Sometimes I am just wiped out though!”

Their level of motivation stemmed from their desire to be successful; successful in their academic studies despite their multiple responsibilities i.e., time, life - obligations (family, school, work).

\subsubsection{Time orientation}

A commonly appearing theme that emerged from the students' data as a primary concern was time. Research has shown that one of the main intrapsychological factors that influence learning is coined, temporal perspective. ${ }^{[14]}$ Temporal perspective is defined as "the manner in which individuals, and cultures, partition the flow of human experience into distinct temporal categories of past, present and future". [15] This time orientation influences how students organized their needs, goals, and concerns.

Many of the graduate student learners specifically stated that they had multiple personal, family and work responsibilities and was concerned about the time to complete their school work while balancing multiple roles, graduate student, family, work, etc. "My biggest concern is balancing work, my other classes and my clinical hours. I am only working part time, but I know time management is going to be my biggest challenge this semester."

"Time." "Working full time with three kids, I worry about having enough time to get everything done, not this course specifically, but school in general."

"Time management." "Time management. I am a single parent, have a full time and part time job as well as taking on full time."

"My biggest concern is juggling work, family and school."

"Staying caught up while balancing work, my family, my other classes and clinicals."

"Juggling it all."

"Struggle with finding balance (no time for self)."

Others referred to time in the context of submitting their work on-time. 
"Being on time multiple assignments, $100 \%$ focusing on one subject or topic. I am taking three classes together and sometimes all the exams and assignments fall under same day/week."

"Being on time for an assignment."

Some of the students further elaborated that their concern related to the issue of time and their ability to produce quality work as evidenced by "... may not produce quality work due to life, family, school, work commitments." Additional concerns were also shared. Specifically, students expressed time as it relates to the time needed to write their papers/assignments and the time required in taking three courses their first semester of graduate school. In addition to time, "understanding technology, not tech savvy" and/or concerned about their computer skills sharing "... limited understanding of informatics and as a result concerned that the assignments may be difficult as a result of the limited knowledge." Similarly, students expressed,

"My biggest concern is that I am not very tech savvy. I feel like I am from old school so it might take me more time than usual. But I am pretty sure I can do it."

"That I may not remember my IT training!"

"Not very computer savvy and software confuses me."

"I would say the terminology would be my biggest concern. I know how to use the computer and the basics of it. When I start reading about gigabytes, megabytes, ROM and RAM, its gets confusing. Maybe the course will help me clarify these terms so I have a better understanding."

Future time orientation was identified in students' responses to why they wanted to earn their master's degree, level of motivation, needs, and concerns as well.

"It seems like the natural progression of my career. I enjoy learning, and have a hard time visualizing myself not being a student. I know this will be great for not only my future, but my family's as well."

"I want to advance in my career and open up more employment possibilities in the future. I am also wanting to learn more and not become stagnant in my current position. There is also the need for financial gain and flexibility in terms of future opportunities, location, position, privileges and responsibility."
"I would like to formally learn how to be an educator, while also preparing for my nursing future after I leave bedside nursing."

\subsubsection{Autonomy/Role change}

Among the survey questions, the researchers also asked students, "Why do you want to earn your master's degree?" The emergent theme derived from student responses was autonomy and role change.

"It has always been my dream to have a higher degree, I want to teach and practice, and I want to earn a better living so that I can send my children to school."

"By earning my master's degree, I will have more career advancement opportunities."

"I want to advance my career."

"Want to advance my role in the community, move to an outpatient setting and develop long term relationships with my patients and their families."

"Further my career, more independent practice, and better working hours."

"I love outpatient Cardiology and want to be an NP for the practice that I worked for. As an RN in an outpatient setting, I felt very limited in that role and wanted to advance my degree so I could do more and be more for my patients."

\subsubsection{Caring}

Thematic patterns revealed all elements of caring and caring behaviors. Statements reflected students had a need for a caring presence from faculty and a desire to care for others.

"To provide care to a larger population."

"I think I will not be forever a nurse working at bedside and I believe through earning this degree, I will be able to share my knowledge, skills and help mold the new generation of nightingales that will greatly take care of me, my family and entire community."

"Thank you for taking the time to care about your students!"

"I strive to be a nurse who not only cares intimately about my patients, but also cares for the well-being of my colleagues."

\subsubsection{Authentic engagement/communication}

When students were asked what they need from faculty to be successful, the theme, authentic engagement, emerged. Permeated throughout the responses were their perceived 
need of the role of the faculty to provide guidance, availability, encouragement, organization, reminders, communication and feedback.

"Timely response."

"Feedback."

"A learning environment that is not one to harm but to help!"

"I just need someone also cheering on my success in grad school."

"Clear communication."

"Concise expectations and constructive comments to help me improve."

"Clear expectations, explanations, and timely feedback on assignments."

"Patience." “... I would also like to get feedback on the assignments so that I can learn and improve based on the feedback." "Guidance."

"Availability and creating an interactive learning environment."

"Availability to answer questions."

"I need availability, patience, instruction, encouragement and reassurance."
"Be available when needed."

"I appreciate a professor that is organized. I have found online learning environments are the toughest when the professor or student is not organized."

The students expressed that the role of the faculty member is to provide a learning environment that is based on open communication and authentic engagement, and, this was the primary basis for their perceived needs further illuminating their self-reported needs for their academic success. Additional concerns expressed were as follows:

"My biggest concern is that the healthcare system is forever changing."

"The biggest issue of it all is my fear that I can't remember anything right now and I about to start practicums, will I be a success, how do I do it, etc."

Table 2 outlines the quantified themes derived from the GLSAQ student responses.

Table 2. Quantified themes from GSLAQ $(\mathrm{N}=120)$

\begin{tabular}{|c|c|c|}
\hline Overarching Themes & Subthemes/Recurrent Thematic Text/Nouns & Data Reduction \\
\hline \multirow{4}{*}{ 1. Motivation } & \multirow{2}{*}{ Intrinsic: } & Goal(s) $n=29$ \\
\hline & & Baby $n=2$ \\
\hline & \multirow{2}{*}{ Extrinsic: } & Work $\mathrm{n}=118$ Family $\mathrm{n}=33$ \\
\hline & & Children $\mathrm{n}=13$ Kids $\mathrm{n}=5$ \\
\hline 2. Time Orientation & $\begin{array}{l}\text { time } n=188 \\
\text { time management } n=18\end{array}$ & Time \\
\hline 3. Autonomy/Role Change & $\begin{array}{l}\text { opportunities } n=11 \\
\text { advance } n=28 \\
\text { change } n=18 \\
\text { career } n=33 \\
\text { more } n=68 \\
\text { autonomy } n=5 \\
\text { role } n=14 \\
\text { bedside } n=7\end{array}$ & Independence and role change \\
\hline 4. Caring & $\begin{array}{l}\text { care, caring } n=114 \\
\text { “to provide” } n=27 \\
\text { passion } n=14 \\
\text { love } n=29\end{array}$ & Caring \\
\hline 5. Authentic Engagement/ Communication & $\begin{array}{l}\text { available } n=29 \\
\text { help } n=138 \\
\text { communication } n=25 \\
\text { support } n=17 \\
\text { expectations } n=39 \\
\text { clear/clarity } n=30 \\
\text { organization } n=15 \\
\text { feedback } n=18\end{array}$ & $\begin{array}{l}\text { Engagement and } \\
\text { Communication }\end{array}$ \\
\hline
\end{tabular}




\section{Discussion}

Adult learning espoused by Knowles ${ }^{[9]}$ enhances the need to know students where they are and apply "andragogy" learning theory. As Knowles stated, "that as an individual matures, his need and capacity to be self-directing, to utilize his experience in learning, to identify his own readiness to learn, and to organize his learning around life problems, increases steadily from infancy to pre-adolescence, and then increasingly rapidly during adolescence.” (p. 43)

The repetitive themes that emerged from the data consistently show the importance of Knowles ${ }^{\text {[16] }}$ theoretical assumptions that adult learners' self-concept moves along a continuum from dependent to self-directed and students' "experiences become an increasingly rich resource for learning" (p. 44). The graduate students' expressions of improving their knowledge base, career status, and bettering their lives confirms Knowles' assertion that "learners see education as a process of developing increased competence to achieve their full potential in life and they want to be able to apply whatever knowledge and skill they gain today to living more effectively tomorrow" (p. 44). Occurrences of textual responses time $(n=188)$ and time orientation $(n=18)$ were the highest number of responses from graduate students which clearly demonstrates Knowles' assertion that, adults enter education with a different time perspective than children which changes how adults perceive their learning and thus learning must have an 'immediacy of application'. [10]

Ellis ${ }^{[2]}$ concluded "the success of graduate education depends on a student-faculty relationship based on integrity, trust, and support" (p. 575). This highlights the importance of including a questionnaire such as the GSLAQ used in this study to 'get to know your students'. McCall, Padron, \& Andrews ${ }^{[17]}$ posited instructors (and librarians) will need to address the needs of adult students by using instructional practices that are based on andragogical concepts to ensure students receive a quality education. The students in this study were diverse and it cannot be assumed they are digital natives. Furthermore, age is no indication of a student's abilities. Accurate and honest assessment of students' learning needs informs educators when designing instructional modules along with coursework that includes group activities. Students' declarations that they are 'not tech savvy' provides important information for educators to plan orientation, course syllabi, and learning modules with multimodal content that includes text, video, and kinesthetic approaches to maximize learning. The information gained from the GSLAQ also reveals students' personal interests and talents. This data is useful because Kennette and Redd ${ }^{[18]}$ identified one of the shortcomings of the online environment for presence is depersonalization. Students' personal interest and

Published by Sciedu Press talents provides faculty with information to use while engaging students in dialogue and written responses and fosters a deeper understanding between faculty to student. Personal interests and talents student data also helps faculty group learners either homogenously (for developmental tasks) or heterogeneously (other learning) that cut across age, occupation, sex, status, and other characteristics. ${ }^{[10]}$

The findings of the theme, authentic engagement, is also supported by the literature emphasizing teaching presence. ${ }^{[19,20]}$ From a theoretical standpoint (orientation to learning), Pappas $^{[12]}$ stated "mature learners prefer to engage in eLearning experiences that help them to solve problems they encounter on a regular basis." Concerns expressed in this study regarding the limited technological skills are congruent with Knowles' ${ }^{[10]}$ theoretical assumption of the learner experience, and other studies that frequently report similar technological concerns from stemming from an online course. ${ }^{[21-23]}$ Congruent with the literature, Millennials are comfortable with technology as they grew up with instantaneous communication in the form of email and text messages. Whereas the Generation Xers, while they used technology, their communication methods differ. Regardless of their preferences, one commonality is that students want timely communication, and feedback ${ }^{[5]}$ which is one of the key needs identified by the students in this study.

Time management is a commonly expressed concern of students globally. Mirzaei, Oskouie, and Rafii ${ }^{[24]}$ examined Iranian nursing students and how they manage their time while focusing on school and their personal lives. "Unidirectional time management" was identified as a way to balance the stress associated with school and academic tasks without a lot of time. This is congruent with this study's findings which confirms that time management and lack of time is a reality that nursing students face concluding that if students are able to effectively manage their time that they will reduce stress and are able to engage in extracurricular activities.

Time management has been identified as a challenge for students in a variety of disciplines. Soares ${ }^{[25]}$ stated that "they [students] have little scheduling flexibility because of work and family obligations" (p. 8). Further challenges expressed by graduate students in non-nursing (geography) programs can be applied to other graduate programs. ${ }^{[26]}$ Students expressed time management as one of the major challenges for graduate students stating, "Feelings of having too much to do and not enough time in the day are common in graduate school" (p. 68). The challenges were ranked and revealed that time management was identified as number one, workload falling in the middle 3rd percentile, and employment falling in the 2 nd percentile which is congruent with this 
study's findings. Similarly, Kremer ${ }^{[27]}$ examined the relationship between school, work, family, conflict, and stress and found that school was identified as a source of stress when students are working and managing their family role demands. This further highlights the challenges and need for students to balance work and school because it can be difficult to balance school, work, and a personal life. Interestingly, Martinez, Ordu, Della Sala, and McFarlane ${ }^{[28]}$ found that full-time single doctoral students without children faced more challenges in efforts to obtain a school-work-life balance in comparison to their peers with families. This is something that was unexpected.

\subsection{Faculty application}

The findings, based on the responses shared by students in the Graduate Student Learning Assessment Questionnaire, can assist faculty in providing a meaningful and supportive learning environment. A seminal quote by $\mathrm{Kral}^{[29]}$ eloquently stated:

"If we ask people to look for deficits, they will usually find them, and their view of the situation will be colored by this. If we ask people to look for successes, they will usually find it, and their view of the situation will be colored by this" ${ }^{\text {"29] }}$ (p. 32).

Understanding students' concerns as well as their perceptions of what they need from faculty to be successful helped faculty better communicate with students in subsequent course sections to provide the needed support for future informatics students. The next semester, faculty provided resources to address many of the GSLAQ concerns. A voice-over Power Point Presentation on 'strategies for success' was created for subsequent semesters to help future graduate students with time management, stress, self-care, and helpful hints such as backing up computer data, starting assignments early, etc. The information is valuable in other tangible ways. When providing assignment and discussion feedback, faculty can review the students' responses and identify expressed concerns. For example, if students express concerns with writing, faculty could address this identified area in the constructive, meaningful feedback to the students. Also, in course announcements and email communications, faculty could take the students' concerns into consideration in an effort to foster an environment of support and concern for student success. This will also help students to feel valued. Since instituting the GSLAQ as a routine questionnaire, students have expressed their appreciation that faculty cared about their thoughts and feelings and felt supported. Several emails have been received stating that they could not believe faculty cared about their thoughts and perceived needs. Authentic engagement, incorporating best practices of teaching as well as the fundamental principles of relationship building, communication, and trust is pivotal to students' success. This also aided in communicating with our students. While our personalized approach mirrors our personal teaching philosophy, it relates to our caring philosophy which is the premise of our school of nursing. Ralph Waldo Emerson said it best: "The secret in education lies in respecting the student". ${ }^{[30]}$ The GSLAQ provides an objective means by which to understand the students' perception of their individual needs.

\subsection{Implications}

Engaging students in an online environment is necessary for students to feel connected. ${ }^{[31]}$ 'Know thy student' allows the opportunity for an open reciprocal dialogue as well as engages the students and enhances open communication and feedback. Students are not a number, they are real students with the real-life issues and everyone is important. Additionally, the onus is on the faculty to create a course that is organized which will help with students' time management. Additionally, creating a learning community that is engaging where students feel valued can be accomplished by incorporating an assessment similar to the GSLAQ. Students' motivation can be supported through open communication and collaboration as well as encouragement focusing on the students' strengths when providing meaningful feedback.

\section{Conclusion}

While a variety of methods have been suggested by Instructional Designers and faculty members, the researchers found that the GSLAQ, the "getting to know you" questionnaire was very enlightening and can help better meet the learning needs of the student population. The authors hope that this manuscript will inspire others to 'know thy student' so that faculty can better communicate with the adult learner.... and ultimately, maximize one's teaching in the online environment. In closing, Palmer ${ }^{[32]}$ states, "We must teach from who we are." The authors encourage others to be a great teacher! You will never regret caring. "Better than a thousand days of diligent study is one day with a great teacher" (Japanese Proverb).

\section{Conflicts of Interest Disclosure}

The author declares that there is no conflict of interest statement. 


\section{REFERENCES}

[1] Prensky M. Digital natives, digital immigrants: Part 1. On the Horizon. 2001; 9(5): 1-6. https://doi.org/10.1108/1074812011 0424816

[2] Ellis HC. Graduate education in psychology: Past, present, and future. American Psychologist. 1992; 47: 570-576. https ://doi .org/10 .1037/0003-066X.47.4.570

[3] Pelz B. (My) Three principles of effective online pedagogy. Journal of Asynchronous Learning Networks. 2004; 8(3): 103-116.

[4] Sunal DW, Sunal CS, Odell MR, et al. Research-supported best practices for developing online learning. The Journal of Interactive Online Learning. 2003; 2(1): 1-40. Available from: http: //www.ncolr.org/jiol/issues/pdf/2.1.1.pdf

[5] Bain S, Fedynich L, Knight M. The successful graduate student: A review of the factors for success. Journal of Academic and Business Ethics. Jan 2011; 3(7): 1-9.

[6] Fedynich L, Bain SF. Mentoring the successful graduate student of tomorrow. Research in Higher Education Journal. 2011; 12: 1-7.

[7] American Association of Community Colleges. Reclaiming the American dream: A report from the 21st-Century Commission on the future of community colleges. Washington, DC: Author; 2012.

[8] Gardner SK. The development of doctoral students: Phases of challenge and support. ASHE Higher Education Report. 2009; 34(6): $1-14$.

[9] Knowles MS. The adult learner: A neglected species. Houston, Texas: Gulf Publishing Company; 1973.

[10] Knowles MS, Associates. Andragogy in action. Applying modern principles of adult education. San Francisco, CA: Jossey-Bass; 1984.

[11] McGregor L, Miller HR, Mayleben MA, et al. Similarities and differences between "traditional" and "nontraditional" college students in selected personality characteristics. Bulletin of Psychonomic Society. 1991; 29(2): 128-130. https://doi.org/10.3758/BF03335213

[12] Pappas C, eLearning Industry. 9 Tips to apply adult learning theory to eLearning. 2014, Aug. Available from: https://elearningindustry.com/9-tips-apply-adu lt-learning-theory-to-elearning

[13] Polit DF, Beck CT. Nursing research: Generating and assessing evidence for nursing practice (10th Ed.). Philadelphia, PA: Lippincott, Williams, \& Wilkins; 2016.

[14] Romero M. The temporal perspective in higher education learners: Comparison between online and onsite learning. European Journal of Open, Distance and e-Learning. 2014; 17(1): 190-209. https : //doi.org/10.2478/eurodl-2014-0013

[15] Zimbardo PG, Keough KA, Boyd JN. Present time perspective as a predictor of risky driving. Personality and Individual Differences. 1997; 23: 1007-1023. https://doi.org/10.1016/S0191-886 9 (97) $00113-\mathrm{X}$

[16] Knowles M. The modern practice of adult education: From pedagogy to andragogy (Revised and Updated).Englewood Cliffs, NJ: Cambridge Adult Education; 1988.
[17] McCall RC, Padron K, Andrews C. Evidence-based instructional strategies for adult learners: A review of the literature. Codex (2150086X). 2018; 4(4): 29-47.

[18] Kennette LN, Redd BR. Instructor presence helps bridge the gap between online and on campus learning. College Quarterly. Fall 2015; $18(4)$

[19] Afolabi RO. Emphasizing instructor presence in digital learning environments. In S. D’Agustino (Ed.), Creating teacher immediacy in online learning environments (pp.37-54). Hershey, PA: IGI Global.

[20] Orcut JM, Dringus LP. Beyond being there: Practices that establish presence, engage students and influence intellectual curiosity in a structured online learning environment. Online Learning. 2017; 21(3): $15-35$

[21] Gillett-Swan J. Supporting and engaging the isolated learner. Journal of Learning Design. 2017; 10(1): 20-30. https ://doi.org/10.5 204/jld.v9i3. 293

[22] Kebritchi M, Lipschuetz A, Santiague L. Issues and challenges for teaching successful online courses in higher education: A literature review. Journal of Educational Technology Systems. 2017; 46(1): 4-29. https://doi.org/10.1177/0047239516661713

[23] Wilhelm S, Rodehorst T, Young S, et al. Students' perceptions of the effectiveness of an asynchronous on-line seminar. Journal of Professional Nursing. 2003; 1(5): 313-319. https ://doi .org/10.101 6/S8755-7223(03)00102-9

[24] Mirzaei T, Oskouie F, Rafii F. Nursing students' time management, reducing stress and gaining satisfaction: A grounded theory study. Nursing \& Health Sciences. 2012; 14(1): 46-51. PMid:22293018 https ://doi.org/10.1111/j.1442-2018.2011.00661.x

[25] Soares L. Post-traditional learners and the transformation of postsecondary education: A manifesto for college leaders. 2013. Available from: http://www. acenet.edu/news-room/Pages/ Post-traditional-Learners-and-the-Transformation-o fPostsecondary-Ed.aspx

[26] Schlemper MB. Challenges and coping in graduate school. Geographical Bulletin. 2011; 52(2): 67-72.

[27] Kremer I. The relationship between school-work-family-conflict, subjective stress, and burnout. Journal of Managerial Psychology. 2016; 31(4): 805. https://doi.org/10.1108/JMP-01-2015-0014

[28] Martinez E, Ordu C, Della Sala MR, et al. Striving to obtain a schoolwork-life balance: The full-time doctoral student. International Journal of Doctoral Studies. 2013.

[29] Kral R. Strategies that work: Techniques for solutions in the schools Milwaukee, WI: Brieg Family Therapy Center. 1989.

[30] Emerson RW, Emerson EW (Editor). The complete works of Ralph Waldo Emerson, Volume 3. Boston, MA: Houghton Mifflin; 1903.

[31] Dixson M. Creating effective student engagement in online courses: What do students find engaging? Journal of the Scholarship of Teaching and Learning. 2010; 10(2): 1-13.

[32] Palmer PJ. The heart of a teacher: Identity and integrity in teaching. Change. 1997; 29(6): 14-21. https://doi.org/10.1080/0009 1389709602343 